\title{
Clinical features of hepatitis B e-antigen positive chronic hepatitis B patients co-existing precore and/or basal core promoter mutations
}

\author{
Li-Bo Yan ${ }^{\ddagger 1}$, Xiao-Qiong Tang ${ }^{\ddagger 1}$, Qing-Bo Zhang ${ }^{2}$, Xia Zhu ${ }^{1}$, Lang Bai ${ }^{1}$, Ling-Yao Du ${ }^{1}$, \\ En-Qiang Chen ${ }^{1} \&$ Hong Tang *,1 \\ ${ }^{1}$ Center of Infectious Diseases, West China Hospital, Sichuan University, Chengdu 610041, PR China \\ ${ }^{2}$ Department of Forensic Pathology, Medical School of Basic \& Forensic Sciences, Sichuan University, Chengdu 610041, PR China \\ *Author for correspondence: Tel.: +862 885422 650; Fax: +862 885423 052; htang6198@hotmail.com \\ ${ }_{\ddagger}^{\ddagger}$ Authors contributed equally
}

\begin{abstract}
Aim: Characterize the clinical features of treatment-naive hepatitis B e-antigen (HBeAg)-positive chronic hepatitis $B(C H B)$ patients harboring either precore $(P C)$ or basal core promoter $(B C P ; P C / B C P)$ mutations. Methods: Alanine aminotransferase, HBsAg, HBV-DNA, HBV genotypes, PC/BCP mutations and liver stiffness measurement were assessed for 186 treatment-naive HBeAg-positive CHB patients. Results: PC/BCP mutations were found in $40.31 \%$ of the treatment-naive HBeAg-positive CHB patients. Patients with PC/BCP mutations showed significantly higher alanine aminotransferase and liver stiffness measurement levels. The serum HBsAg and HBV DNA levels in patients with BCP mutations were significantly lower than those in patients with wild-type virus. $P C / B C P$ mutations were more prevalent in patients in immune clearance phase than those in immune tolerance phase. Conclusion: The emergences of PC/BCP mutations possibly indicate that $\mathrm{HBeAg}$ positive patients are experiencing the phase of immune clearance.
\end{abstract}

First draft submitted: 15 May 2018; Accepted for publication: 12 July 2018; Published online: 16 August 2018

Keywords • basal core promoter $\bullet$ HBeAg-positive $\bullet$ hepatitis B virus • immune clearance $\bullet$ immune tolerance - precore

Hepatitis $B$ is a major public health problem worldwide. Approximately 257 million persons worldwide are chronic hepatitis $\mathrm{B}(\mathrm{CHB})$ patients, particularly in low-and middle-income countries [1]. $\mathrm{CHB}$ is the leading cause of liver cirrhosis and primary liver cancer in China [2]. The clinical outcome differs among individuals with CHB [3]. The pathogenesis of $\mathrm{CHB}$ infection can be attributed to the complex interaction between the host's immune response and viral proteins.

Hepatitis B e-antigen ( $\mathrm{HBeAg}$ ) is a key viral protein which is translated from the precore (preC) transcript of $\mathrm{HBV}$ genome. $\mathrm{HBeAg}$ is capable of eliciting immune tolerance and involving in upregulating viral replication and facilitating the chronicity and persistence of infection in the host [4]. The presence of $\mathrm{HBeAg}$ is accepted as a classical indicator of $\mathrm{HBV}$ replication. The loss of $\mathrm{HBeAg}$ and the production of anti-HBe antibodies are considered a line of demarcation in the natural history of CHB.

$\mathrm{HBV}$ replicates via reverse transcription of pregenomic RNA, during which the proof-reading function is missing, making it prone to mutations [5]. Mutations in the HBV genome are frequent in CHB patients. The mechanisms of $\mathrm{HBeAg}$ seroconversion are not fully understood. The precore $(\mathrm{PC})$ and basal core promoter $(\mathrm{BCP})$ regions regulate $\mathrm{HBV}$ genomic replication and preC mRNA synthesis. $\mathrm{HBeAg}$ is translated by preC mRNA. Therefore, mutations in the preC and $\mathrm{BCP}$ regions may impact $\mathrm{HBeAg}$ seroconversion. In this study, we focused on mutations in the preC and $\mathrm{BCP}$ regions.

A predominant variant contains a $\mathrm{G}$ to A change at nucleotide 1896 in preC region (G1986A), which results a premature stop codon. This mutation prevents translation to a full-length preC protein and the production of HBeAg antigen is completely abolished. The most common BCP mutations result in a paired A to $\mathrm{T}$ at nt1762

Future Medicine 
and $\mathrm{G}$ to $\mathrm{A}$ at nt1764 (A1762T/G1764A) [6]. Consequently, this A1762T/G1764A mutation inhibits the preC mRNA synthesis and decreases the production of HBeAg [7]. Since the G1896A and A1762T/G1764A mutations compromise the $\mathrm{HBeAg}$ production, they are more expressed in $\mathrm{HBeAg}$ negative patients than in $\mathrm{HBeAg}$ positive patients with chronic $\mathrm{HBV}[8]$.

PreC and BCP mutations in patients with chronic HBV infection have been studied extensively. One report has described the frequency of $\mathrm{PC} / \mathrm{BCP}$ mutations in $\mathrm{CHB}$ patients, especially HBeAg-negative patients [9]. Their association with the development of liver cirrhosis, primary liver cancer and liver failure has also been proposed [10,11]. Most of these studies selected HBeAg negative and/or HBeAg-positive patients with chronic HBV, including those who received antiviral therapy. Antiviral treatment may have an impact on the frequency of PC/BCP mutations. However, data regarding the frequency of PC/BCP mutations in treatment-naive HBeAg-positive patients are still limited.

Recently, a study by Pan et al. [12] described the clinical features of CHB in treatment-naive HBeAg positive Asian patients, which coexisting preC and/or BCP (PC/BCP) mutations. In contrast to traditional observations, $\mathrm{PC} / \mathrm{BCP}$ mutations were found to be more than $60 \%$ in $\mathrm{HBeAg}$-positive $\mathrm{CHB}$ patients. Current knowledge is still lacking with regard to the effect of $\mathrm{PC} / \mathrm{BCP}$ mutations on host and viral factors in HBeAg positive treatment-naive CHB patients, including serum ALT and HBsAg levels, HBV genotype, viral load and liver stiffness measurement (LSM).

Therefore, this study aimed to characterize the clinical features of $\mathrm{HBeAg}$-positive treatment-naive $\mathrm{CHB}$ patients harboring PC/BCP mutations. The correlations between PC/BCP mutations and ALT, serum HBsAg, HBV DNA level and LSM were achieved accordingly.

\section{Patients}

A total of 186 adult patients with chronic HBV infection were enrolled from April 2010 to June 2012 in the Center of Infectious Disease of West China Hospital of Sichuan University. All of the recruited chronic HBV infection patients were HBeAg positive and treatment naive. Based on 2015 Asian Pacific Association for the Study of the Liver guideline on the management of hepatitis $B$, the enrolled patients were classified into patients in immune tolerance (IT) phase and patients in immune clearance (IC) phase [11].

Exclusion criteria were coinfection with HIV, HCV or HDV; alcohol consumption exceeding $40 \mathrm{~g}$ per day and decompensated liver cirrhosis or hepatocellular carcinoma. Patients receiving antiviral therapy were also excluded because of the possible impact on PC/BCP variants. Clinical information including age, gender and family history was collected. This study was approved by the ethics committee of West China hospital, Sichuan University.

\section{Serologic markers of HBV \& HBV DNA}

Serum samples were tested for quantitative HBsAg titer using chemiluminescent microparticle immunoassay by ARCHITECT HBsAg Kit (Abbott Diagnostics, IL, USA). Antibody to HBsAg, HBeAg and anti-HBe were measured using a microparticle enzyme immunoassay (Abbott Diagnostics, IL, USA). Serum HBV DNA was quantified with quantitative fluorescence PCR (Shanghai Kehua Bio-engineering Co., Ltd, Shanghai, China). HBV DNA levels were expressed as $\log _{10}$ copies $/ \mathrm{ml}$.

\section{HBV genotyping \& detection of BCP \& PC region mutations}

HBV genotypes were measured by fluorescent PCR in the KingMed Diagnostics Laboratory. The fluorescent probes were designed and synthesized based on the sequences of HBV genotypes. Detection of HBV PC and BCP mutations were performed in the Kingmed Diagnostics Laboratory using PCR-Reverse Dot Blot.

\section{Liver stiffness measurement}

LSM was performed using FibroScan as reported [13]. More than 10 valid measurements were obtained for each patient. The median value was recorded for LSM. Measurements with a success rate of less than $60 \%$ or an interquartile range of more than $30 \%$ were considered discarded. The unit of LSM is kilopascals (kPa).

\section{Statistical analysis}

Statistical analyses were performed with SPSS version 20.0 (SPSS, IL, USA). Normally distributed quantitative variables were expressed as the mean \pm standard deviation. Non-normally distributed quantitative variables were expressed as median values (range, minimum-maximum). Qualitative variables were expressed as counts and per- 
Table 1. Clinical characteristics of patients.

\begin{tabular}{|c|c|}
\hline Patient group & Mean \pm SD or $n(\%) ; n=186$ \\
\hline Age, years & $33.26 \pm 8.99$ \\
\hline \multicolumn{2}{|l|}{ Gender, n (\%): } \\
\hline Male & $133(71.50)$ \\
\hline Female & $53(28.50)$ \\
\hline ALT, IU & $32(5-294)$ \\
\hline $\mathrm{TB}, \mu \mathrm{mol} / \mathrm{I}$ & $13.77 \pm 11.68$ \\
\hline B & $123(66.13)$ \\
\hline C & $60(32.26)$ \\
\hline $\mathrm{B} / \mathrm{C}$ & $3(1.61)$ \\
\hline HBV DNA, $\log _{10}$ copies/ml & $7.30 \pm 1.26$ \\
\hline $\mathrm{HBsAg}, \log _{10} \mathrm{IU} / \mathrm{ml}$ & $4.12 \pm 0.86$ \\
\hline $\mathrm{BCP} / \mathrm{PC}$ & $11(5.91)$ \\
\hline \multicolumn{2}{|l|}{ HBV immune phase } \\
\hline IT phase & $127(68.28)$ \\
\hline IC phase & $59(31.72)$ \\
\hline LSM, kPa & $8.56 \pm 6.82$ \\
\hline
\end{tabular}

centages. HBsAg and HBV DNA were log-transformed. Normally distributed continuous variables were compared by Student's t-test. Non-normally distributed quantitative data were analyzed with the Mann-Whitney U test. Qualitative variables were analyzed by $\chi^{2}$ test. p-values less than 0.05 were considered statistically significant.

\section{Results}

\section{Patient characteristics}

A total of 186 eligible patients were consisting of 127 patients in IT phase and 59 patients in IC phase. Basic characteristics are shown in Table 1 . The PC/BCP mutations were detected in $40.31 \%$ of $\mathrm{HBeAg}$-positive treatmentnaive patients with chronic HBV infection. The prevalence of HBV WT, PC mutation, BCP mutations and combined PC/BCP mutations was 59.68\% (111/186), 20.97\% (39/186), 13.44\% (25/186) and 5.91\% (11/186), respectively. There were $123(123 / 186,66.13 \%)$ patients infected with genotype B, $60(60 / 186,32.26 \%)$ patients infected with genotype $\mathrm{C}$ and 3 patients coinfected with genotypes $\mathrm{B}$ and $\mathrm{C}(3 / 186,1.61 \%)$.

\section{Clinical characteristics of HBeAg-positive CHB patients with PC/BCP mutations versus those with wild-type virus}

When mutations were analyzed in the study, patients were classified into one of the following four categories based on their mutation point(s): wild-type; PC mutation; BCP mutations and combined PC/BCP mutations. The median ALT values were 25 (5-219), 47 (10-294), 53 (9-215) and 68 (8-146) in patients with wild-type virus, PC mutation, BCP mutations and combined PC/BCP mutations, respectively (Table 2). The corresponding mean LSM values were $6.48 \pm 4.04,10.24 \pm 10.25,12.29 \pm 5.21$ and $15.74 \pm 8.63 \mathrm{kPa}$ (Table 2), respectively. Patients with any PC or BCP mutations had significantly higher ALT and LSM values (Figure 1A \& D).

HBeAg-positive patients with PC mutations had similar median $\mathrm{HBsAg}$ values to those with wild-type HBV ( 4.16 vs $4.33 \log 10 \mathrm{IU} / \mathrm{ml}, \mathrm{p}=0.26$ ). Mean serum $\mathrm{HBsAg}$ values in patients with $\mathrm{BCP}$ mutation or combined $\mathrm{PC} / \mathrm{BCP}$ mutations were significantly lower than in patients with wild-type virus $\left(3.34\right.$ vs $4.33 \log _{10} \mathrm{IU} / \mathrm{ml}, \mathrm{p}$ $<0.001 ; 3.74$ vs $4.33 \log _{10} \mathrm{IU} / \mathrm{ml}, \mathrm{p}=0.002$ )(Figure 1B). Mean serum HBV DNA levels in patients with BCP mutations or combined $\mathrm{PC} / \mathrm{BCP}$ mutations were also significantly lower than in patients with wild-type virus (6.43 vs $7.42 \log _{10}$ copies $/ \mathrm{ml}, \mathrm{p}<0.001 ; 7.16$ vs $7.42 \log _{10}$ copies $/ \mathrm{ml}, \mathrm{p}=0.012$ )(Figure $1 \mathrm{C}$ ). 

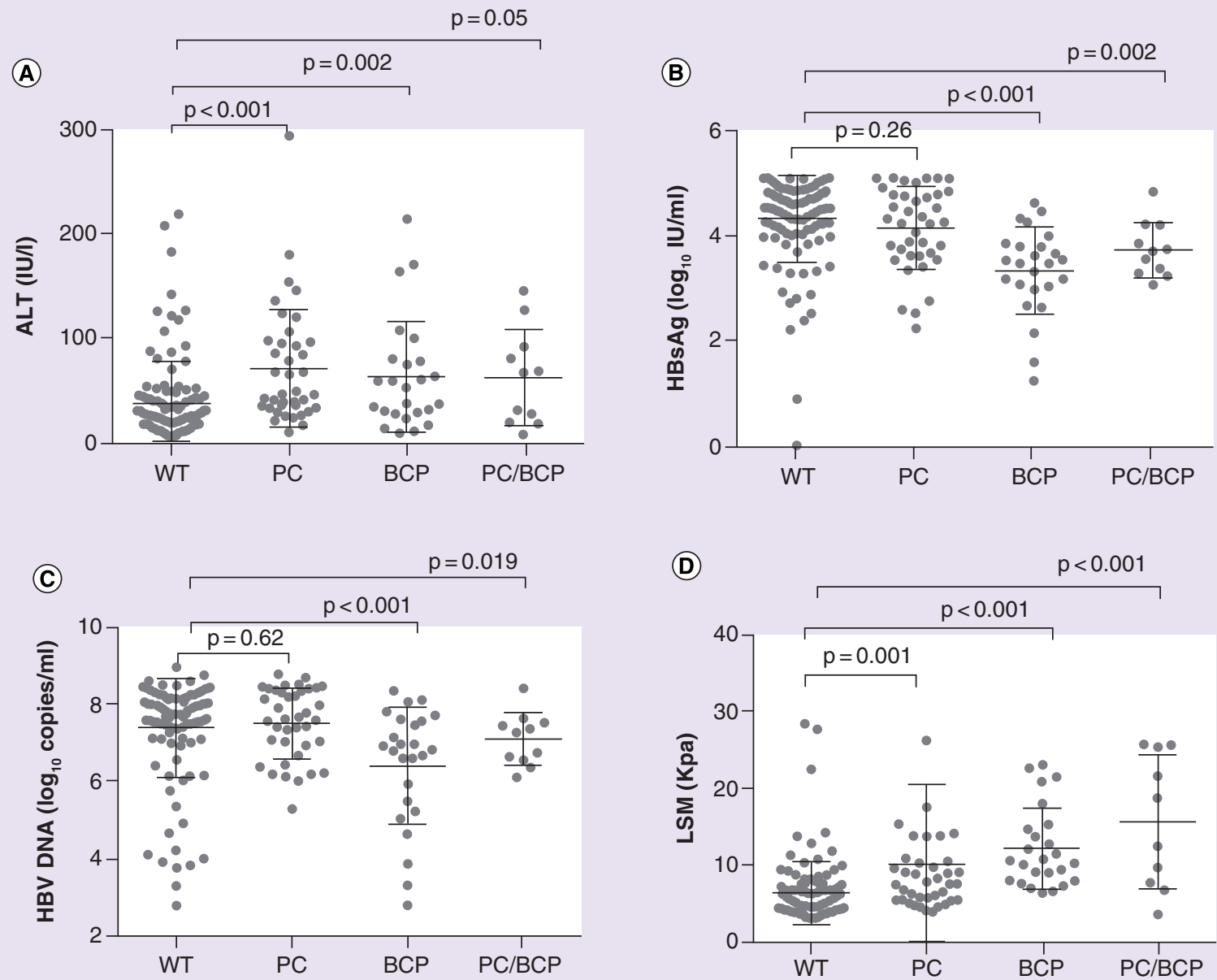

Figure 1. Comparison of clinical characteristics in the HBeAg-positive chronic hepatitis B patients with nt1762/1764 wild-type, PC mutant, BCP mutant and PC/BCP mutant HBV infection. (A) ALT (IU/I) (B) HBsAg ( $\left.\log _{10} \mathrm{lU} / \mathrm{ml}\right)$ (C) HBV DNA (log 10 copies/ml) (D) LSM (kPa). BCP: Basal core promoter; LSM: Liver stiffness measurement; PC: Precore; WT: Wild type.

The precore \&/or basal core promoter mutations in different immune phases of CHB

The prevalence of PC and/or BCP mutations stratified by different immune phases of patients with chronic HBV infection is shown in Figure 2A. The prevalence of HBV WT, PC mutation, BCP mutations and combined BCP/PC mutations was $71.65 \%$ (91/127), 14.17\% (18/127), 10.24\% (13/127) and 3.94\% (5/123), respectively, in patients of the IT phase. The corresponding prevalence was $33.90 \%$ (20/59), 35.59\% (21/59), 20.34\% (12/59) and $10.17 \%(6 / 59)$, respectively, for patients of the IC phase. PC and/or BCP mutations were more prevalent in HBeAg-positive CHB patient in the IC phase than in the IT phase $(39 / 59$ vs $36 / 129, \mathrm{p}<0.001)$.

$\mathrm{PC} \& /$ or BCP mutations in patients with genotype $\mathrm{B}$ and $\mathrm{C}$ infection

The prevalence of $\mathrm{PC}$ and/or BCP mutations stratified by HBV genotype is shown in Figure 3A. The prevalence of HBV WT, PC mutation, BCP mutations and combined BCP/PC mutations was $65.86 \%(81 / 123), 25.20 \%$ $(31 / 123), 6.50 \%(8 / 123)$ and $2.43 \%(3 / 123)$, respectively, in patients with genotype $\mathrm{B}$. The corresponding prevalence was $50 \%(30 / 60), 10 \%(6 / 60), 28.33 \%(17 / 60)$ and $11.67 \%(7 / 60)$ in patients with genotype C, respectively. $\mathrm{BCP}$ mutations (including $\mathrm{BCP}$ mutations and $\mathrm{PC} / \mathrm{BCP}$ mutations) were more prevalent in patients with genotype $\mathrm{C}$ than genotype $\mathrm{B}(24 / 60$ vs $11 / 123, \mathrm{p}<0.001)$. For PC mutations (including PC mutations only and PC/BCP mutations), there was no statistically significant difference between the two genotypes (13/60 vs $34 / 123, \mathrm{p}=0.385)$. Among PC mutation patterns, genotype $\mathrm{B}$ was more prevalent, similar to the wild-type 

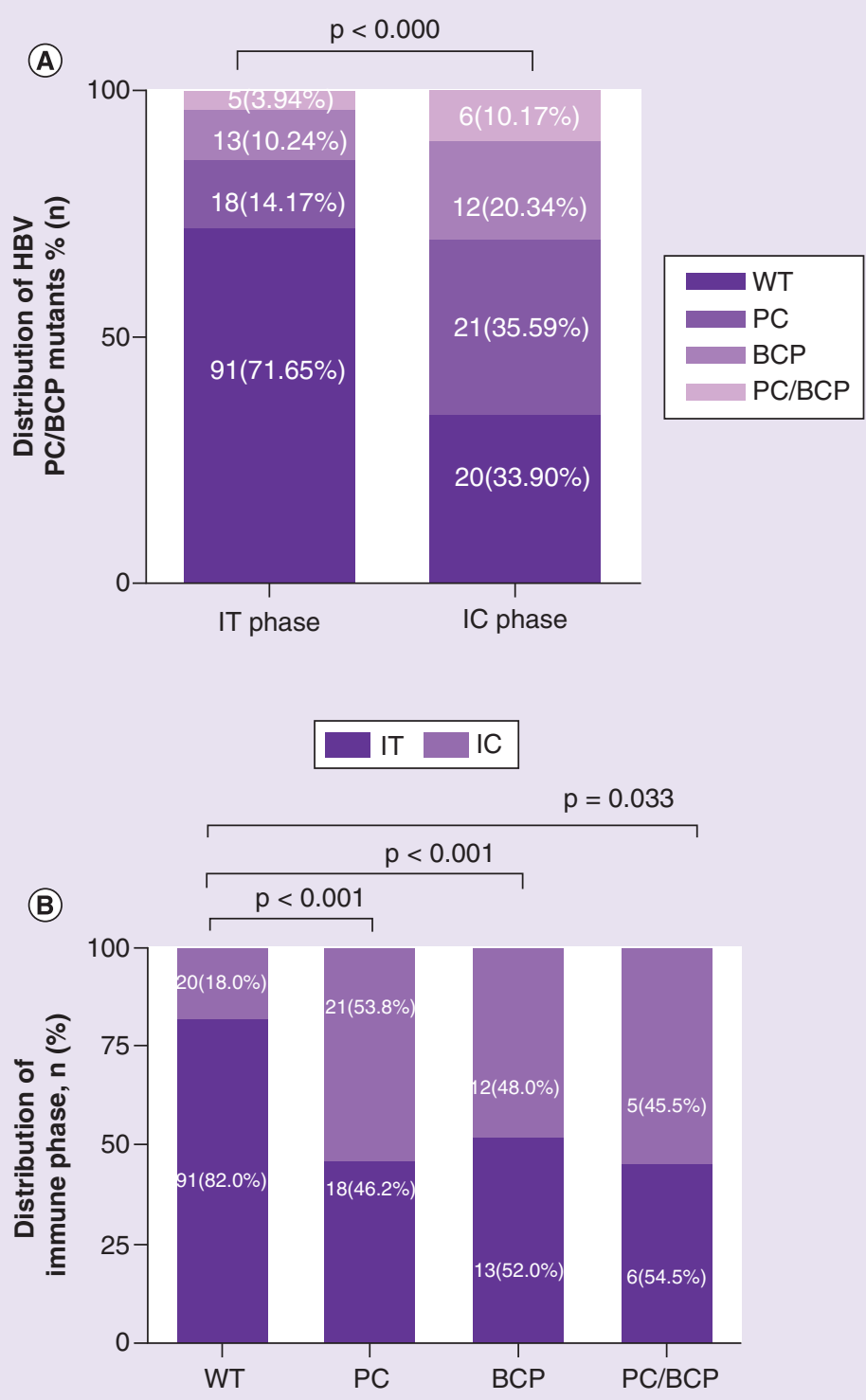

Figure 2. The patterns of distribution of PC and BCP mutations in patients with IT phase versus IC phase.

BCP: Basal core promoter; PC: Precore; IC: Immune clearance phase; IT: Immune tolerance phase; WT: Wild type.

pattern $(31 / 39$ vs $81 / 111, \mathrm{p}=0.143)$. Genotype $\mathrm{C}$ was more prevalent in $\mathrm{BCP}$ and $\mathrm{PC} / \mathrm{BCP}$ mutations patterns (17/25 vs 30/111, p < 0.001; 7/11 vs 30/111, p < 0.001) (Figure 3B).

\section{Discussion}

PC and BCP mutations have been investigated widely in patients with chronic HBV infection, especially in those with $\mathrm{HBeAg}$ disappears and seroconversion to anti-HBe [14]. Therefore, PC/BCP mutations are expected to be common in $\mathrm{HBeAg}$-negative patients. However, data regarding the frequency of PC/BCP mutations in treatmentnaive $\mathrm{HBeAg}$-positive patients is still limited. In this study, a total of $40.31 \%(74 / 186)$ of patients harbored HBV PC or BCP mutations. The prevalence of PC/BCP mutations in this study is lower than two previous studies in China [15,16]. Yan et al. [17] reported that PC/BCP mutations existed in $65.10 \%(125 / 192)$ of treatmentnaive $\mathrm{HBeAg}$ positive Chinese patients. Pan et al. [12] found PC/BCP mutations in 60.45\% of HBeAg-positive treatment-naive Asian patients. In line with Yan et al. [17], we found that BCP mutations were more prevalent in patients with genotype $\mathrm{C}$ than genotype $\mathrm{B}$. The predominant $\mathrm{HBV}$ genotype was $\mathrm{B}$ in the present study, while 

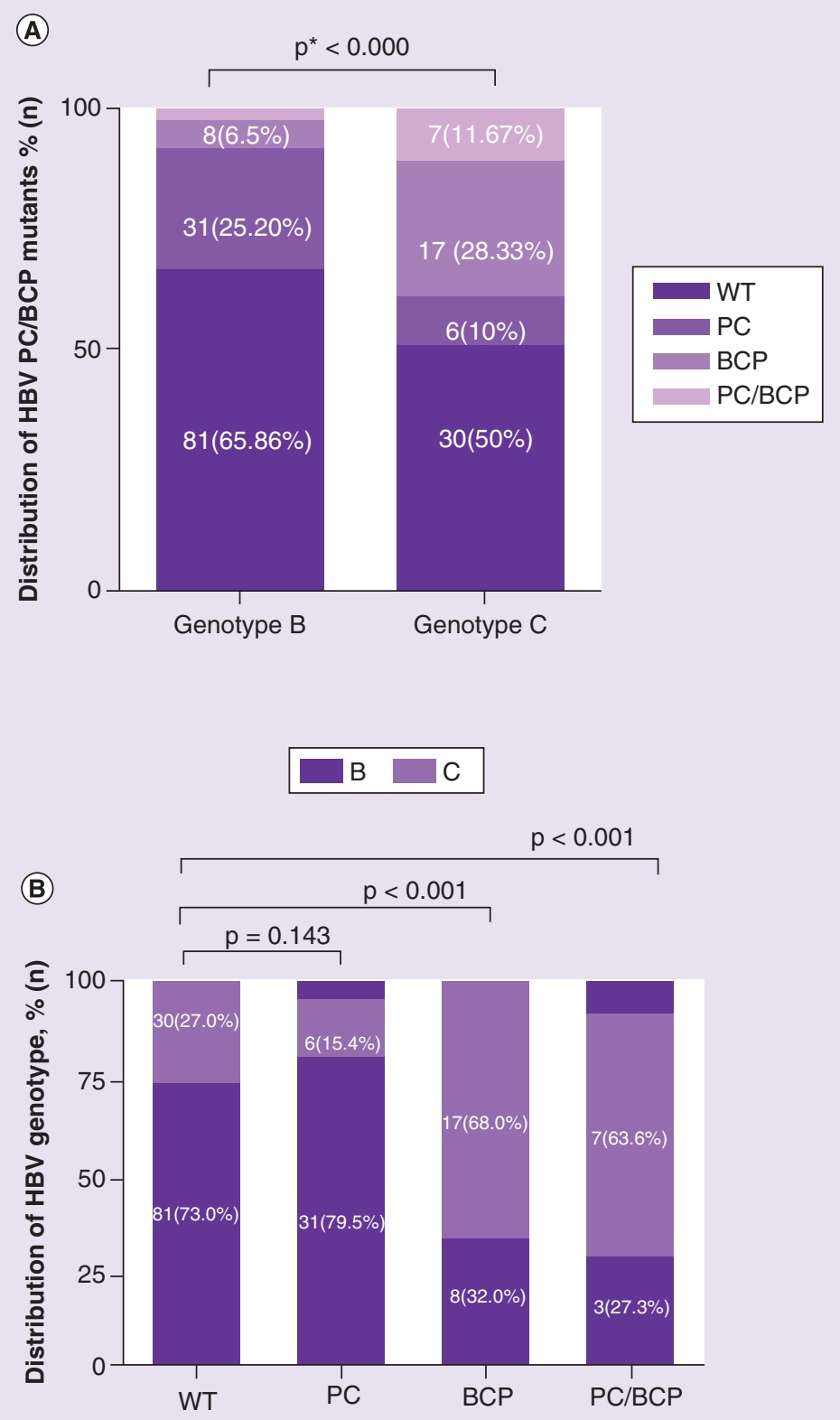

Figure 3. The patterns of distribution of $P C$ and $B C P$ mutations in patients with genotype $B$ versus genotype $C$. BCP: Basal core promoter; PC: Precore; WT: Wild type.

the predominant HBV genotype was $\mathrm{C}$ in the study by Yan et al. [17]. In this study, patients who received antiviral therapy were excluded because the treatment may influence the host immune pressure on HBV and increase the prevalence of $\mathrm{PC} / \mathrm{BCP}$ mutations. $\mathrm{HBV}$ genotype, treatment-naive experience and ethnicity may account for the varied prevalence of $\mathrm{PC} / \mathrm{BCP}$ mutations in $\mathrm{HBeAg}$-positive cases.

It was surprising that the rate of PC mutation was higher than that of BCP mutations in our population with positive $\mathrm{HBeAg}$. Previous studies demonstrated that HBV genotype B predicted the presence of PC mutation, while genotype $\mathrm{C}$ predicted the presence of BCP mutations [18,19]. In HBeAg-positive patients, we also observed that $\mathrm{BCP}$ mutations were associated with genotype $\mathrm{C}$ infection. The present results are consistent with previous studies. However, the predominant HBV genotype was B in this study. This may be the reason for a slightly higher proportion of the overall prevalence of PC mutation. 
Table 2. Clinical characteristics of hepatitis B e-antigen-positive chronic hepatitis B patients with wild-type versus precore/basal core promoter mutations.

\begin{tabular}{|c|c|c|c|c|}
\hline Characteristics & Wild-type $(n=111)$ & PC mutation $(n=39)$ & BCP mutations $(n=25)$ & $\begin{array}{l}\text { Combined PC/BCP mutations } \\
(n=11)\end{array}$ \\
\hline Age, years & $32.23 \pm 7.89$ & $33.28 \pm 10.09$ & $34.84 \pm 10.53$ & $39.91 \pm 9.69$ \\
\hline \multicolumn{5}{|l|}{ Gender, n (\%): } \\
\hline - Male & 79 (71.17) & $28(71.79)$ & $20(80.00)$ & $6(54.55)$ \\
\hline ALT, IU/I & $25(5-219)$ & $47(10-294)$ & $53(9-215)$ & $68(8-146)$ \\
\hline $\mathrm{TB}, \mu \mathrm{mol} / \mathrm{l}$ & $13.56 \pm 10.74$ & $15.24 \pm 17.04$ & $13.47 \pm 6.38$ & $11.42 \pm 6.36$ \\
\hline \multicolumn{5}{|l|}{ HBV genotype: } \\
\hline$-B$ & $81(72.97)$ & $31(79.49)$ & $8(32.00)$ & $3(27.27)$ \\
\hline$-\mathrm{C}$ & $30(27.03)$ & $6(15.38)$ & $17(68.00)$ & $7(63.64)$ \\
\hline$-B / C$ & 0 & $2(5.13)$ & 0 & $1(9.09)$ \\
\hline HBV DNA, $\log _{10}$ copies/ml & $7.42 \pm 1.27$ & $7.53 \pm 0.91$ & $6.43 \pm 1.52$ & $7.16 \pm 0.51$ \\
\hline $\mathrm{HBsAg}, \log _{10} \mathrm{IU} / \mathrm{ml}$ & $4.33 \pm 0.82$ & $4.16 \pm 0.78$ & $3.34 \pm 0.82$ & $3.74 \pm 0.52$ \\
\hline LSM, kPa & $6.48 \pm 4.04$ & $10.24 \pm 10.25$ & $12.29 \pm 5.21$ & $15.74 \pm 8.63$ \\
\hline
\end{tabular}

BCP: Basal core promoter; LSM: Liver stiffness measurement; PC: Precore.

The principal finding of this study was that $\mathrm{HBeAg}$-positive patients with BCP mutations were more likely to have lower serum HBV DNA levels compared with those patients with wild-type HBV. The previous study demonstrated that the HBV strain with BCP mutations supported a higher level of pregenomic RNA transcription and HBV DNA replication, compared with the wild-type strain in vitro.

As to the impact of BCP mutations on viral replication, variants in the core promoter regions can enhance genome replication capacity and reduce $\mathrm{HBeAg}$ expression in vitro through regulation by different liver-enriched transcription factors involved in viral transcription [20,21]. However, there is a contradiction of enhanced in vitro replication and reduced in vivo viremia. Parekh et al. [22] amplified full-length HBV genomes by PCR from sera of $\mathrm{HBeAg}$ positive individuals, cloned into vectors, transfected and detected HBV replication. They found that clones derived from highly viremic individuals showed low replication capacity in vitro, while some clones derived from low-viremia individuals had much higher replication capacity in vitro. It indicated that under the influence of the interaction between the virus and the host immune system, the BCP mutations affect viral replication in ways that are not captured in vitro [23].

The relationship between liver fibrosis and PC/BCP mutations in HBeAg-positive patients is also accessed in this study. LSM by FibroScan is reliable for detecting advanced liver fibrosis and cirrhosis in patients with $\mathrm{CHB}[24,25]$. Among HBeAg-positive patients, individuals with any PC or BCP mutations had significantly higher LSM compared with individuals with WT. Although elevated ALT has a slight impact on LSM, 81.7\% of patients enrolled in this study had normal ALT. Therefore, the elevated LSM represented advanced liver fibrosis. It indicated that treatment-naive HBeAg-positive individuals with any PC or BCP mutations might have advanced liver fibrosis.

In our study, PC/BCP mutations were more prevalent in patients with IC-phase than IT-phase infection. It suggest that among patients with $\mathrm{HBeAg}$ positivity, unlike those with wild-type $\mathrm{HBV}$ who are in the immune tolerance phase, patients with PC/BCP mutations are in the immune clearance phase and are experiencing greater immune pressure, leading to a lower level of viremia and $\mathrm{HBs} \mathrm{Ag}$. Our results demonstrated that the emergence of PC/BCP mutations was associated with the strong immune clearance for the HBeAg-positive patients.

Nevertheless, we are aware that there are several limitations in this study. First, the sample size of only 186 patients was relatively small. Despite the small sample size, we detected valuable clinical applications in chronic HBV patients with PC/BCP mutations. Second, longitudinal investigation is needed to give a better comprehension of the roles of PC/BCP mutations in natural history of chronic HBV infection. Third, PC/BCP mutations are not detected by sequencing. Fortunately, PCR-reverse Dot Blot is a accurate, reproducible for detection of PC/BCP mutations.

\section{Conclusion}

Our study showed that PC/BCP mutations frequently occurred, even in treatment-naive HBeAg-positive patients. HBV BCP mutations were associated with low levels of serum HBsAg and HBV DNA but with high levels of 
ALT and LSM. The emergence of PC/BCP mutations indicates that HBeAg-positive patients are experiencing the phase of immune clearance.

\section{Future perspective}

Future large longitudinal studies are needed to investigate the long-term clinical outcomes when PC/BCP mutations are detected in HBeAg-positive patients as it may impact the natural history in such patients.

\section{Executive summary}

- Precore/basal core promoter (PC/BCP) mutations are frequently detected in hepatitis $\mathrm{B}$ e-antigen (HBeAg)-negative chronic hepatitis B (CHB) patients, but little is known about their prevalence and clinical features in $\mathrm{HBeAg}$-positive CHB patients especially in China.

- The PC/BCP mutants are also frequent (40.31\%) in treatment-naive HBeAg-positive CHB patients.

- HBV BCP mutations are associated with low levels of both serum HBsAg and HBV DNA, but a higher alanine aminotransferase levels and liver stiffness measurement values in treatment-naive HBeAg-positive CHB patients.

- The emergence of $\mathrm{PC} / \mathrm{BCP}$ mutations indicates that $\mathrm{HBeAg}$-positive patients are experiencing the phase of immune clearance.

\section{Acknowledgements}

We thank all the patients who participated in the study. We also thank all the staff (Center of Infectious Diseases, West China Hospital of Sichuan University) for their assistance in this study.

Financial \& competing interests disclosure

This work was supported by National Science and Technology Major Project of China (no.2017ZX10202203-007-004 and 2017ZX10202203-008-005). Theauthors have no other relevant affiliations or financial involvement with any organization or entity with a financial interest in or financial conflict with the subject matter or materials discussed in the manuscript apart from those disclosed.

The authors declare that they have no competing interests.

\section{Open access}

This work is licensed under the Attribution-NonCommercial-NoDerivatives 4.0 Unported License. To view a copy of this license, visit http://creativecommons.org/licenses/by-nc-nd/4.0/

\section{References}

1. WHO. Guidelines for the prevention, care and treatment of persons with chronic hepatitis b infection. WHO, Geneva, Switzerland, 134 (2015).

2. Iloeje UH, Yang HI, Su J, Jen CL, You SL, Chen CJ. Predicting cirrhosis risk based on the level of circulating hepatitis B viral load. Gastroenterology 130(3), 678-686 (2006).

3. Chen CJ, Yang HI, Su J et al. Risk of hepatocellular carcinoma across a biological gradient of serum hepatitis B virus DNA level. JAMA 295(1), 65-73 (2006).

4. Alexopoulou A, Karayiannis P. HBeAg negative variants and their role in the natural history of chronic hepatitis B virus infection. World J. Gastroenterol. 20(24), 7644-7652 (2014).

5. Harrison TJ. Hepatitis B virus: molecular virology and common mutants. Semin. Liver Dis. 26(2), 87-96 (2006).

6. Takahashi K, Aoyama K, Ohno N et al. The precore/core promoter mutant (T1762A1764) of hepatitis B virus: clinical significance and an easy method for detection. J. Gen. Virol. 76(Pt 12), 3159-3164 (1995).

7. Carman WF, Jacyna MR, Hadziyannis $S$ et al. Mutation preventing formation of hepatitis B e-antigen in patients with chronic hepatitis B infection. Lancet 2(8663), 588-591 (1989).

8. Wang XL, Ren JP, Wang XQ, Wang XH, Yang SF, Xiong Y. Mutations in pre-core and basic core promoter regions of hepatitis B virus in chronic hepatitis B patients. World J. Gastroenterol. 22(11), 3268-3274 (2016).

9. Liu CJ, Cheng HR, Chen CL et al. Effects of hepatitis B virus precore and basal core promoter mutations on the expression of viral antigens: genotype B vs C. J. Viral Hepat. 18(10), e482-e490 (2011).

10. Ren X, Xu Z, Liu Y et al. Hepatitis B virus genotype and basal core promoter/precore mutations are associated with hepatitis B-related acute-on-chronic liver failure without pre-existing liver cirrhosis. J. Viral Hepat. 17(12), 887-895 (2010). 
11. Liu Y, Zhong Y, Zou Z et al. Features and clinical implications of hepatitis B virus genotypes and mutations in basal core promoter/precore region in 507 Chinese patients with acute and chronic hepatitis B. J. Clin. Virol. 47(3), 243-247 (2010).

12. Pan CQ, Dai E, Bhamidimarri KR, Zeng Z, Yin P. clinical features of chronic hepatitis b in treatment-naive asian patients with positive hbeag and coexisting precore and/or basal core promoter mutations. J. Clin. Gastroenterol. 51(3), 261-267 (2017).

13. Yan LB, Zhu X, Bai L et al. Impact of mild to moderate elevations of alanine aminotransferase on liver stiffness measurement in chronic hepatitis B patients during antiviral therapy. Hepatol. Res. 43(2), 185-191 (2013).

14. Hakami A, Ali A, Hakami A. Effects of hepatitis B virus mutations on its replication and liver disease severity. Open Virol. J. 7, 12-18 (2013).

15. Vutien $\mathrm{P}$, Trinh HN, Nguyen $\mathrm{K}$ et al. Precore and basal core promoter mutations in Asian American patients with hepatitis $B$ e-antigen-positive chronic hepatitis B. Aliment Pharmacol. Ther. 37(4), 464-472 (2013).

16. Chu CJ, Keeffe EB, Han SH et al. Prevalence of HBV precore/core promoter variants in the United States. Hepatology 38(3), 619-628 (2003).

17. Yan $\mathrm{CH}$, Zhao CY, Ding $\mathrm{H}$ et al. Hepatitis B virus basal core promoter mutations A1762T/G1764A are associated with genotype $\mathrm{C}$ and a low serum HBsAg level in chronically-infected HBeAg-positive Chinese patients. Antiviral Res. 96(2), 108-114 (2012).

18. Chen $\mathrm{CH}$, Lee $\mathrm{CM}$, Hung $\mathrm{CH}$ et al. Clinical significance and evolution of core promoter and precore mutations in HBeAg-positive patients with HBV genotype B and C: a longitudinal study. Liver Int. 27(6), 806-815 (2007).

19. Chu CJ, Hussain M, Lok AS. Hepatitis B virus genotype B is associated with earlier HBeAg seroconversion compared with hepatitis B virus genotype C. Gastroenterology 122(7), 1756-1762 (2002).

20. Tang H, Raney AK, McLachlan A. Replication of the wild type and a natural hepatitis B virus nucleocapsid promoter variant is differentially regulated by nuclear hormone receptors in cell culture. J. Virol. 75(19), 8937-8948 (2001).

21. Leng XH, Chen EQ, Du LY et al. Biological characteristics of the A1762T/G1764A mutant strain of hepatitis B virus in vivo. Mol. Med. Rep. 12(4), 5141-5148 (2015).

22. Parekh S, Zoulim F, Ahn SH et al. Genome replication, virion secretion, and E-antigen expression of naturally occurring hepatitis B virus core promoter mutants. J. Virol. 77(12), 6601-6612 (2003).

23. Cheng Y, Seet BL, Ong CS et al. Are in vitro hepatitis B core promoter mutations important for clinical alterations in viral load? Antiviral Res. 69(3), 142-151 (2006).

24. Xu X, Su Y, Song R et al. Performance of transient elastography assessing fibrosis of single hepatitis B virus infection: a systematic review and meta-analysis of a diagnostic test. Hepatol. Int. 9(4), 558-566 (2015).

25. Li Y, Huang YS, Wang ZZ et al. Systematic review with meta-analysis: the diagnostic accuracy of transient elastography for the staging of liver fibrosis in patients with chronic hepatitis B. Aliment Pharmacol. Ther. 43(4), 458-469 (2015). 
